\title{
Cataract induction by administration of nitroglycerin in cardiac patients through imbalance in redox status
}

This article was published in the following Dove Press journal:

Therapeutics and Clinical Risk Management

27 September 2016

Number of times this article has been viewed

Rehab M El-Gharabawy ${ }^{1,2}$

Amira S Ahmed 1,3

Amal H Al-Najjar ${ }^{4}$

'Pharmacology and Toxicology Department, College of Pharmacy, Qassim University, Buraydah, Kingdom of Saudi Arabia; ${ }^{2}$ Pharmacology and Toxicology Department, College of Pharmacy, Tanta University, Tanta, ${ }^{3}$ Hormone Department, National Research Center, Giza, Egypt; ${ }^{4}$ Pharmacy Services Department, Security Forces Hospital, Riyadh, Kingdom of Saudi Arabia
Correspondence: Rehab M El-Gharabawy Pharmacology and Toxicology Department, College of Pharmacy, Tanta University, El-bahr St, 33347, Tanta, Egypt

Tel +204096654234I840

Email drrehab200932@yahoo.com
Purpose: The objective of this study was to evaluate the role of nitroglycerin in the pathogenesis of cataract.

Design: Prospective study.

Patient and methods: This study was performed in adults from tertiary Saudi Arabian hospitals ( 34 males and 26 females in each group, aged from 40 to 60 years), who were divided into four groups with an equal number of subjects (control group, cardiac group, idiopathic cataract group, and a group of cardiac patients using nitroglycerin and with cataracts). Fasting glucose concentrations, blood glycated hemoglobin levels, lipid profiles, and levels of nitrite, conjugated dienes (CD), thiobarbituric acid reactive substances (TBARS), superoxide dismutase (SOD), and reduced glutathione (GSH) were determined.

Results: Treatment of cardiac patients with nitroglycerin produced an imbalance in their systemic redox status, leading to the development of cataracts, which was reflected by a significant increase in the levels of nitrite, $\mathrm{CD}$, and TBARS and a significant decrease in SOD activity and GSH, compared with idiopathic cataract patients. The results of correlation studies and multiple regression analysis revealed a significant positive correlation between different biochemical parameters (GSH, SOD, TBARS, CD, and nitrite) in the blood and lens in both idiopathic cataract patients and cardiac patients treated with nitroglycerin.

Conclusion: The study points to the relative and predictive effects of nitric oxide derived from nitroglycerin in the development of cataract in the presence of the oxidative stress induced by nitroglycerin treatment.

Keywords: nitroglycerin, oxidative stress, cataract, nitrite, lens

\section{Introduction}

Nitroglycerin (glyceryl trinitrate, GTN) has been used to treat angina pectoris, myocardial infarction, and heart failure for a significant period of time, and still acts as one of the main therapies for these conditions. ${ }^{1}$

Several metabolic pathways have been identified through which GTN is enzymatically reduced to produce nitric oxide (NO) or NO precursors. ${ }^{2,3}$ These enzymes include xanthine oxidase, ${ }^{4}$ glutathione $S$-transferase, and, more recently, mitochondrial aldehyde dehydrogenase (ALDH-2). ${ }^{2}$ Indeed, the main action of ALDH-2 in the mitochondrial electron transport chain is that it mediates the conversion of GTN into nitrite $\left(\mathrm{NO}^{-}\right)$in the mitochondria. ${ }^{5}$ Under normal conditions, GTN is bioactivated by ALDH-2 to yield 1,2-glyceryl dinitrate and nitrite, which are then converted to NO, $S$-nitrosothiol, or a related species by the mitochondrial respiratory chain or acidic disproportionation, to induce vasodilation. In addition, GTN induces vasodilation through 
activation of the soluble guanylyl cyclase/cyclic guanosine monophosphate (cGMP)/cGMP-dependent protein kinase I pathway without production of free radicals. Both enzymatic and nonenzymatic mechanisms for GTN metabolism and biotransformation have been reported. Many enzymes are involved in GTN metabolism and biotransformation, including ALDH- $2,{ }^{6}$ the cytochrome p450 enzymes, ${ }^{7}$ xanthine oxidoreductase ${ }^{8}$ and glutathione $S$-transferases. ${ }^{9}$ The reaction of GTN with thiols may also produce vasodilator S-nitrosothiols (SNOs). ${ }^{10} \mathrm{NO}$ and SNOs activate soluble guanylyl cyclase, causing an elevation in the levels of second messenger cGMP in tissues. cGMP-dependent protein kinase I mediates vasodilation by phosphorylating proteins which regulate cellular $\mathrm{Ca}^{2+}$ levels. ${ }^{11}$ GTN can also induce vasodilation through a cGMP-independent pathway. ${ }^{6}$

During bioactivation of GTN through oxidation of essential thiol groups to disulfide, ALDH-2 is inactivated. Restoration of ALDH-2 reductase activity is induced by reducing lipoic acid. Subsequently, the reduced glutathione (GSH)-glutathione reductase system reduces the oxidized form. ${ }^{12}$

Chronic therapeutic use of GTN produces mitochondrial reactive oxygen and reactive nitrogen species (ROS/RNS). The major source of ROS formation is the mitochondria in response to short- and long-term GTN challenges. ${ }^{13,14}$ The diffusion-limited reaction of $\mathrm{NO}$ and superoxide produces peroxynitrite. GTN and/or NO byproducts in the mitochondria may lead to uncoupling of respiration and mitochondrial damage. ${ }^{6}$ Critical thiols, such as the active-site thiols in ALDH-2, are oxidized by increased production of superoxide and other ROS. ${ }^{15}$

GTN bioactivation is inhibited by oxidative stress through inactivation of ALDH-2 or inhibition of the ALDH-2 repair system, which includes lipoic acid as well as the GSH/ GSH reductase system. Moreover, the bioavailability of the vasodilator produced from GTN bioactivation is decreased by superoxide. ${ }^{12}$ A characteristic feature of prolonged GTN administration is the formation of GTN tolerance. A possible explanation is either a decrease in GTN bioconversion into $\mathrm{NO}^{6,16}$ or a decrease in the bioavailability of GTN-derived $\mathrm{NO}$ as a result of enhanced superoxide formation. ${ }^{17}$ Both mechanism-based tolerance and cross-tolerance are reactivated by mitochondrial production of ROS. The contribution of ALDH-2 to GTN tolerance and cross-tolerance remains to be clarified. ${ }^{14}$

Suprapharmacological GTN concentrations cause a significant increase in vascular NO formation, while pharmacological GTN concentrations are not associated with any elevation in NO levels. Increased NO production is possibly related to the "second" GTN pathway, which is not affected by GTN tolerance state. ${ }^{6}$ Increased production of RNS causes nitrosylation reactions, which can cause alterations in the structure of proteins and, thus, impair their normal function. ${ }^{18}$ Thiol, amine, and heme nitrosylation generates $S$-nitrosothiols, nitrosyl heme, and $N$-nitroso compounds, respectively. These reactions suggest new signaling pathways through which NO affects the cell physiology by covalently modifying tissue biomolecules. ${ }^{19,20}$

Paik and Dillon ${ }^{21}$ found modifications of protein structure, which are similar to those found in age-related nuclear cataract, when they incubated nitrite, an end product of NO, with lens $\alpha$-crystallin. Aminoguanidine, an inhibitor of inducible nitric oxide synthase (iNOS), has been demonstrated to suppress cataractogenesis in animal studies. The objectives of this study were to evaluate the role of NO (as a metabolite of GTN) in the pathogenesis of cataract and to estimate the levels of an NO metabolite (nitrite), lipid peroxidation, superoxide dismutase (SOD), and GSH as an indicator of oxidative stress.

\section{Methods}

This study was performed in adults from tertiary Saudi Arabian hospitals. Three hundred cardiac patients were considered for this study, of whom 60 patients had not received nitroglycerin and had cataract ( $2 \%)$. One hundred and twenty cardiac patients were selected in accordance with the inclusion and exclusion criteria. They were divided into two groups (cardiac patients who had not received nitroglycerin and cardiac patients who had received nitroglycerin). Other groups included in the current study were healthy control and idiopathic cataract groups. This study was approved by the hospital committee of the tertiary Riyadh Hospital, Kingdom of Saudi Arabia, and written informed consent was obtained from all the patients included in the study. A preliminary examination of all participants consisted of a brief medical history including details of systemic disease, drug administration, cigarette smoking, trauma, and exposure to ultraviolet radiation. A complete ophthalmic history and examination included an assessment of the morphologic type of any cataract present. All participants in this study had similar dietary habits (including low dietary fat, number of daily meals, and a low salt intake). All participants underwent a full clinical examination.

\section{Inclusion criterion}

Cardiac patients who had been administered nitroglycerin for at least 1 year. 


\section{Exclusion criteria}

Cardiac patients who had been administered nitroglycerin, but were more than 60 years old; prolonged exposure to sunlight (10 months or more); high blood pressure; obesity; previous eye injury or inflammation; previous eye surgery; antioxidants had not been administered in the previous 6 months; smoking; medication or diseases, which induced oxidative stress in the last 2 years (including prolonged use of corticosteroid medications, diabetes, cancer, asthma, chronic bronchitis, osteoarthritis, and hepatitis).

\section{Sample collection}

Approximately $10 \mathrm{~mL}$ of venous blood was collected from the antecubital vein of each subject after overnight fasting and was separated into two aliquots: $5 \mathrm{~mL}$ in a vacutainer tube without any anticoagulant to obtain the serum and the other $5 \mathrm{~mL}$ in a plain vial containing heparin to obtain the plasma. The lenses of affected patients (nucleus plus cortex) were obtained after extracapsular cataract extraction operations and were immediately stored at $-70^{\circ} \mathrm{C}$ until analyzed.

\section{Biochemical analysis}

Fasting glucose levels were measured colorimetrically using the glucose oxidase method reported by Trinder. ${ }^{22}$ Blood glycated hemoglobin was determined according to the method reported by Little et $\mathrm{al}^{23}$ using the Helena GLYCO-Tek affinity column method (Helena Laboratories, Beaumont, TX, USA). Nonesterified fatty acid concentrations were analyzed colorimetrically according to the method described by Schuster and Pilz. ${ }^{24}$ Serum cholesterol concentrations were estimated according to the method reported by Deeg and Ziegenohrm ${ }^{25}$ using a commercial reagent kit (Reactivos Spinreact Company, Girona, Spain). Serum triglyceride concentrations were determined according to the method reported by Fossati and Prencipe ${ }^{26}$ using a commercial reagent kit purchased from Reactivos Spinreact Company. Serum high-density lipoprotein (HDL) cholesterol concentrations were calculated according to the method reported by Norbert. ${ }^{27}$ Serum low-density lipoprotein (LDL) cholesterol levels were calculated using the Friedewald ${ }^{28}$ formula $($ LDL-cholesterol $=$ total cholesterol - triglycerides $/ 5-$ HDLcholesterol).

\section{Nitrite assay}

Nitrite was measured using the Griess reaction. ${ }^{29}$ Briefly, serum samples were diluted fourfold with distilled water and deproteinized using zinc sulfate $(300 \mathrm{~g} / \mathrm{L})$ to give a final concentration of $15 \mathrm{~g} / \mathrm{L}$. After centrifugation, $100 \mu \mathrm{L}$ of the supernatant was applied to a microtiter plate well, followed by addition of $100 \mu \mathrm{L}$ of Griess reagent which was composed of $1 \mathrm{~g} / \mathrm{L}$ sulfanilamide, $25 \mathrm{~g} / \mathrm{L}$ phosphoric acid, and $0.1 \mathrm{~g} / \mathrm{L} N$-1-naphthylethylenediamine. After 10 minutes of color development at room temperature, the absorbance was measured at a wavelength of $540 \mathrm{~nm}$ using a microplate reader (Titertek Multiskan MCC/340; Flow Lab, McLean, VA, USA).

\section{Assay of lipid peroxidation as a measurement of oxidative status Conjugated dienes assay}

Serum conjugated dienes (CD) levels were determined using the method described by Recknagel and Glende. ${ }^{30}$ Lipids were extracted using 2:1 (by volume) chloroform-methanol; the extract was evaporated until dry under a stream of nitrogen and then redissolved in cyclohexane. The cyclohexane solution absorbance was measured at $234 \mathrm{~nm}$. The results were expressed as $\mu \mathrm{mol} / \mathrm{L}$.

Thiobarbituric acid reacting substance (TBARS) assay Serum TBARS concentrations were measured as a lipid peroxidation product using the Kei Satoh method. ${ }^{31}$ Serum proteins were precipitated using trichloroacetic acid and the mixture was heated for 30 minutes in a boiling water bath in the presence of thiobarbituric acid in $2 \mathrm{M}$ sodium sulfate. $n$-Butyl alcohol was used to extract the resulting chromogen and the absorbance of the organic phase was determined at a wavelength of $530 \mathrm{~nm}$.

\section{Enzymatic antioxidant assay - SOD}

Estimation of plasma SOD was performed using the method reported by Kakkar et al. ${ }^{32}$ A mixture of $1.35 \mathrm{~mL}$ of doubledistilled water, $0.1 \mathrm{~mL}$ of phenazine methosulfate, $50 \mu \mathrm{L}$ of plasma, $1.2 \mathrm{~mL}$ of sodium pyrophosphate buffer ( $\mathrm{pH} 8.3$ ), and $0.3 \mathrm{~mL}$ of nitroblue tetrazolium was prepared. The reaction was initiated with $0.2 \mathrm{~mL}$ of NADH solution. After incubation at $39^{\circ} \mathrm{C}$ for 90 seconds, the reaction was terminated using $1 \mathrm{~mL}$ of glacial acetic acid. After the addition of $4 \mathrm{~mL}$ of $n$-butanol, the mixture was centrifuged at 4,000 rpm for 10 minutes. The absorbance of the upper butanol layer was recorded at $560 \mathrm{~nm}$.

\section{Nonenzymatic antioxidant assay - reduced GSH}

The concentration of GSH was determined using a fluorometric method described by Hissin and Hilf. ${ }^{33}$ Briefly, serum samples were deproteinized using an equal volume of 5\% trichloroacetic acid. Then, the samples were centrifuged at 
$10,000 \times g$ for 10 minutes. The GSH levels were determined in $\mu \mathrm{mol} / \mathrm{L}$. GSH standard solution or supernatant $(200 \mu \mathrm{L})$ was added to $2.6 \mathrm{~mL}$ of phosphate-ethylenediaminetetraacetic acid buffer $(5 \mathrm{mM}$ ethylenediaminetetraacetic acid, $0.1 \mathrm{M}$ sodium phosphate, $\mathrm{pH}=8$ ) and $200 \mu \mathrm{L}$ of $1 \mathrm{mg} / \mathrm{mL}$ $O$-phthaldialdehyde. The mixture was incubated at room temperature for 45 minutes. Then, fluorescence detection was performed with excitation and emission at 350 and $418 \mathrm{~nm}$, respectively.

\section{Preparation of lens extract}

Homogenization of the lens was performed on ice using a cold buffer ( $0.2 \mathrm{M}$ potassium phosphate, $60 \mathrm{mM}$ sodium dodecyl sulfate, $137 \mathrm{mM}$ potassium chloride, $\mathrm{pH}$ 7.2). Lipid autooxidation was prevented using ethanolic butylated hydroxytoluene solution $(2 \%, \mathrm{v} / \mathrm{v})$. Centrifugation $\left(12,000 \times g ; 40^{\circ} \mathrm{C}\right.$; 20 minutes) was performed to remove any insoluble material. Biochemical measurements were carried out on an ultraviolet/ visible spectrophotometer (SAFAS 2, Monaco, Monaco).

\section{Determination of lens nitrite levels}

Nitrite levels were measured using the following spectrophotometric method. Lens samples were homogenized in bidistilled water in a Heidolph glass homogenizer at a neutral $\mathrm{pH}$ and centrifuged at $10,000 \times g$ for 10 minutes, after measuring the net weight of each lens. These supernatants were incubated in a water bath for 15 minutes at $80^{\circ} \mathrm{C}$. Insoluble proteins were separated by centrifugation for 30 minutes at 13,000 rpm. The supernatants were analyzed for nitrite using a modified Griess reaction (1\% sulfanilamide solution in $2.5 \%$ phosphoric acid and $0.1 \%$ naphthylethylenediamine). ${ }^{29}$ The reaction product (nitrite) was measured at $541 \mathrm{~nm}$ using a spectrophotometer after incubation for 10 minutes at room temperature. The nitrite level was expressed in nanomoles per $100 \mathrm{mg}$ of lens tissue.

\section{Measurement of lens lipid peroxidation markers}

CD concentrations were assessed in a liposoluble lens extract. ${ }^{34}$ In brief, $50 \mu \mathrm{L}$ of water-insoluble lens material was suspended by vortex-mixing in $1.5 \mathrm{~mL}$ of a chloroformmethanol mixture $(2: 1, \mathrm{v} / \mathrm{v})$ and centrifugation for 5 minutes at $2,000 \times g\left(4^{\circ} \mathrm{C}\right)$. The lower chloroform layer was removed and evaporated until dry under a stream of nitrogen. The absorbance was measured in a quartz-glass cuvette at $\lambda=234 \mathrm{~nm}$ after redissolving the lipid residue in $1 \mathrm{~mL}$ of concentrated cyclohexane. The level of TBARS was determined in a hydrosoluble lens extract. ${ }^{35}$ The absorbance of a pinkish trimethin complex formed during the reaction of Malondialdehyde (MDA) with 2-thiobarbituric acid (70 mM; $\mathrm{NaOH}, 50 \mathrm{mM}$ ) was determined at $\lambda=532 \mathrm{~nm}$.

\section{Determination of lens SOD activity}

SOD activity was determined by measuring the rate of inhibition of adrenaline auto-oxidation to adrenochrome. This was continuously monitored at $25^{\circ} \mathrm{C}$ for 3 minutes at $\lambda=480 \mathrm{~nm}^{36}$

\section{Determination of lens GSH levels}

Tripeptide GSH is the major intracellular nonenzymatic antioxidant and reducing agent. Hydrosoluble lens extract was deproteinized using 10\% metaphosphoric acid. Then, the concentration of GSH was determined using Ellman's reagent. ${ }^{37}$

\section{Statistical analysis}

Findings are expressed as mean \pm standard deviation (SD) and data were analyzed using the Student's $t$-test. One-way analysis of variance was performed followed by a Tukey post hoc test to determine statistically significant differences between groups. A $P$-value of $<0.05$ was considered to indicate significant differences. Correlation studies were performed to analyze the relative and predictive effects of NO levels on the development of nitroglycerininduced cataract in the presence of oxidative stress. The correlations between the studied parameters were assessed to analyze the relative and predictive effects of serum GSH and plasma SOD activity in the development of cataracts in the presence of the oxidative stress induced by nitroglycerin.

\section{Results}

The basic demographic characteristics of the control participants, idiopathic cataract patients, and cardiac patients who received or did not receive nitroglycerin are presented in Table 1.

The cardiac patients were somewhat younger $(<55$ years) and had a slightly higher body mass index, on average, than the healthy controls and idiopathic cataract patients.

In the present study, $57 \%$ of the participants per group were male $(n=34)$ and $43 \%$ were female $(n=26)$. The mean age, sex, educational level, and body mass index were suitably matched between the experimental groups.

The frequency distribution of lifestyle confounding factors was not significantly different between the experimental groups. Twenty percent of the control group $(n=12)$ 
Table I Basic demographic characteristics of control, cardiac patients (not treated with nitroglycerin), and cataract patients

\begin{tabular}{lllll}
\hline Item & Control & $\begin{array}{l}\text { Cardiac patients } \\
\text { (not treated with } \\
\text { nitroglycerin) }\end{array}$ & $\begin{array}{l}\text { Idiopathic } \\
\text { cataract }\end{array}$ & $\begin{array}{l}\text { Nitroglycerin } \\
\text { users with } \\
\text { cataract }\end{array}$ \\
\hline Age & $55.5 \pm 4.3$ & $54.7 \pm 4.9$ & $55.1 \pm 4.8$ & $55.1 \pm 4.6$ \\
Sex & $34(57)$ & $34(57)$ & $34(57)$ & $34(57)$ \\
$\quad$ Male $(\%)$ & $26(43)$ & $26(43)$ & $26(43)$ & $26(43)$ \\
$\quad$ Female $(\%)$ & $48(80)$ & $45(75)$ & $50(83)$ & $47(78)$ \\
$\begin{array}{l}\text { Education } \\
\text { Low }(\%)\end{array}$ & $12(20)$ & $15(25)$ & $10(17)$ & $13(22)$ \\
High $(\%)$ & $24.1 \pm 2.9$ & $24.5 \pm 2.8$ & $24.3 \pm 3.7$ & $24.8 \pm 3.0$ \\
BMl $\left(\mathrm{kg} / \mathrm{m}^{2}\right)$ & & & \\
\hline
\end{tabular}

Notes: Values are presented as mean \pm SD for age and BMI, $n=60$ for each group. Sex and education are presented as number and percent.

Abbreviations: BMI, body mass index; SD, standard deviation.

patients were highly educated, whereas $80 \%$ possessed a low level of education. Twenty-five percent of the cardiac patients were highly educated, whereas $75 \%$ possessed a low level of education. Only $17 \%$ of the idiopathic cataract patients were highly educated, whereas $83 \%$ possessed a low level of education. Twenty-two percent of cardiac patients treated with nitroglycerin were highly educated, whereas $78 \%$ were not (Table 1).

Table 2 shows that there were no significant changes among certain biochemical variables between the experimental groups, including fasting blood glucose levels, glycated hemoglobin A, total cholesterol, HDL, LDL, and triglycerides.

In the present study, serum CD levels and TBARS, which are markers for oxidative stress, were found to be significantly increased in the cardiac patients not treated with nitroglycerin and in the idiopathic cataract patients compared with the control group (51\% and 53\%, and $22 \%$ and $15 \%$, respectively). Cardiac patients treated with nitroglycerin showed a significant increase in serum CD and TBARS levels, compared with the cardiac patients not treated with nitroglycerin and the idiopathic cataract patients (14\% and
$12 \%$, and $62 \%$ and $73 \%$, respectively) and the control group (70\% and 98\%, respectively) (Table 3).

However, the levels of plasma SOD, a marker of enzymatic antioxidant activity, were found to be significantly decreased in the cardiac patients not treated with nitroglycerin and in the idiopathic cataract patients compared with the control group (20\% and $22 \%$, respectively). Cardiac patients treated with nitroglycerin showed a significant decrease in the levels of SOD, compared with the cardiac patients not treated with nitroglycerin and the idiopathic cataract patients (37\% and 34\%, respectively) and the control group (49\%) (Table 3).

In addition, the levels of serum GSH, a marker of nonenzymatic antioxidant activity, were found to be significantly decreased in the cardiac patients not treated with nitroglycerin and in the idiopathic cataract patients compared with the control group (10\% and $12 \%$, respectively). Cardiac patients treated with nitroglycerin showed a significant decrease in serum GSH, compared with the cardiac patients not treated with nitroglycerin and the idiopathic cataract patients (27\% and $32 \%$, respectively) and the control group (40\%) (Table 3).

Table 2 Biochemical analysis of control, cardiac patients (not treated with nitroglycerin), and cataract patients

\begin{tabular}{|c|c|c|c|c|c|c|}
\hline Item & Control & $\begin{array}{l}\text { Cardiac patients } \\
\text { (not treated with } \\
\text { nitroglycerin) }\end{array}$ & $\begin{array}{l}\text { Idiopathic } \\
\text { cataract }\end{array}$ & $\begin{array}{l}\text { Nitroglycerin } \\
\text { users with } \\
\text { cataract }\end{array}$ & F value* & $P$-value \\
\hline Fasting blood glucose (mmol/L) & $5.4 \pm 0.3$ & $5.5 \pm 0.1$ & $5.4 \pm 0.1$ & $5.3 \pm 0.2$ & 1.6 & 0.2 \\
\hline HbAIc (\% of hemoglobin) & $5.2 \pm 0.1$ & $5.1 \pm 0.2$ & $5.3 \pm 0.1$ & $5.4 \pm 0.2$ & 0.8 & 0.4 \\
\hline Total cholesterol (mmol/L) & $4.8 \pm 0.4$ & $4.7 \pm 0.3$ & $4.8 \pm 0.8$ & $4.7 \pm 0.5$ & 0.1 & 0.9 \\
\hline HDL-cholesterol (mmol/L) & $1.2 \pm 0.1$ & $\mathrm{I} . \mathrm{I} \pm 0.2$ & $1.3 \pm 0.2$ & $1.2 \pm 0.2$ & 0.2 & 0.9 \\
\hline LDL-cholesterol (mmol/L) & $3.3 \pm 0.1$ & $3.2 \pm 0.2$ & $3.1 \pm 0.1$ & $3.1 \pm 0.2$ & 1.7 & 0.2 \\
\hline Triglyceride (mmol/L) & $1.5 \pm 0.2$ & $1.5 \pm 0.1$ & $1.6 \pm 0.2$ & $1.5 \pm 0.3$ & 0.1 & 0.9 \\
\hline
\end{tabular}

Notes: Values are presented as mean $\pm S D, n=60$ for each group. $* P<0.05$ calculated by one-way ANOVA.

Abbreviations: ANOVA, analysis of variance; HbAIc, glycated hemoglobin A; HDL-cholesterol, high-density lipoprotein cholesterol; LDL-cholesterol, low-density lipoprotein cholesterol; SD, standard deviation. 
Table 3 Blood biomarkers of oxidative stress and nitrite in control, cardiac patients (not treated with nitroglycerin), and cataract patients

\begin{tabular}{|c|c|c|c|c|c|c|}
\hline Item & Control & $\begin{array}{l}\text { Cardiac patients } \\
\text { (not treated with } \\
\text { nitroglycerin) }\end{array}$ & $\begin{array}{l}\text { Idiopathic } \\
\text { cataract }\end{array}$ & $\begin{array}{l}\text { Nitroglycerin } \\
\text { users with } \\
\text { cataract }\end{array}$ & F value* & $P$-value \\
\hline $\operatorname{SOD}(\mathrm{U} / \mathrm{mL})$ & $4.0 \pm 0.9$ & $3.2 \pm 0.8^{\mathrm{a}}$ & $3.1 \pm 0.2^{\mathrm{a}}$ & $2.0 \pm 0 . I^{a, b}$ & 110.3 & 0.000 \\
\hline $\mathrm{GSH}(\mu \mathrm{mol} / \mathrm{mL})$ & $2.1 \pm 0.1$ & $1.9 \pm 0.1^{\mathrm{a}}$ & $1.8 \pm 0.1^{\mathrm{a}}$ & $1.4 \pm 0.3^{\mathrm{a}, \mathrm{b}}$ & 189.9 & 0.000 \\
\hline $\mathrm{CD}(\mathrm{nmol} / \mathrm{mL})$ & $1.7 \pm 0.1$ & $2.6 \pm 0.4^{\mathrm{a}}$ & $2.5 \pm 0.1^{\mathrm{a}}$ & $2.9 \pm 0.1^{\mathrm{a}, \mathrm{b}}$ & 292.2 & 0.000 \\
\hline TBARS (nmol/mL) & $7.1 \pm 0.1$ & $8.7 \pm 1.2^{\mathrm{a}}$ & $8.1 \pm 0.1^{\mathrm{a}}$ & $14.1 \pm 0.3^{\mathrm{a}, \mathrm{b}}$ & I,523.8 & 0.000 \\
\hline Nitrite $(\mu \mathrm{mol} / \mathrm{L})$ & $31.4 \pm 0.4$ & $38.4 \pm 8.8^{a}$ & $37.1 \pm 1.0^{\mathrm{a}}$ & $53.4 \pm 2.2^{\mathrm{a}, \mathrm{b}}$ & 252.3 & 0.000 \\
\hline
\end{tabular}

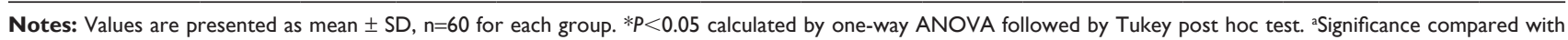
control group. 'Significance compared with idiopathic cataract.

Abbreviations: ANOVA, analysis of variance; CD, conjugated dienes; GSH, reduced glutathione; SD, standard deviation; SOD, superoxide dismutase; TBARS, thiobarbituric acid reacting substances.

Serum nitrite levels were found to be significantly higher in the cardiac patients not treated with nitroglycerin and in the idiopathic cataract patients compared with the control group ( $22 \%$ and $18 \%$, respectively). Cardiac patients treated with nitroglycerin showed a significant increase in serum nitrite levels (1.6-fold), compared with the cardiac patients not treated with nitroglycerin and the idiopathic cataract patients (39\% and $44 \%$, respectively) and the control group (70\%) (Table 3).

Table 4 demonstrates a significant positive correlation between serum CD, serum TBARS, and serum nitrite in the cardiac patients who were not treated with nitroglycerin. On the other hand, a significant negative correlation was found between plasma SOD activity and serum nitrite in the cardiac patients who were not treated with nitroglycerin. A significant negative correlation between plasma SOD activity, serum TBARS, and serum GSH was revealed in the idiopathic cataract patients. In addition, a significant negative correlation was found between serum GSH and serum nitrite in the idiopathic cataract patients. However, a significant positive correlation between serum TBARS, serum nitrite, and serum CD was observed in the idiopathic cataract patients. Cardiac patients treated with nitroglycerin showed a significant positive correlation between plasma SOD activity and serum GSH, between serum TBARS and serum nitrite, and between serum CD, serum TBARS, and serum nitrite. In contrast, a significant negative correlation was found between plasma SOD activity and serum TBARS, serum nitrite, and serum $\mathrm{CD}$ in the cardiac patients treated with nitroglycerin. In addition, a significant negative correlation was found between serum GSH and serum TBARS, serum nitrite, and serum $\mathrm{CD}$ in the cardiac patients treated with nitroglycerin.

The cardiac patients treated with nitroglycerin showed a significant increase in the concentration of lens CD and TBARS, compared with the idiopathic cataract patients

Table 4 Correlation between different biochemical parameters in control, cardiac patients (not treated with nitroglycerin), and cataract patients

\begin{tabular}{lllll}
\hline Item & Control & $\begin{array}{l}\text { Cardiac patients } \\
\text { (not treated with } \\
\text { nitroglycerin) }\end{array}$ & $\begin{array}{l}\text { Idiopathic } \\
\text { cataract }\end{array}$ & $\begin{array}{l}\text { Nitroglycerin } \\
\text { users with } \\
\text { cataracts }\end{array}$ \\
\hline Bivariate & $r_{12}-0.05$ & $r_{12} 0.06$ & $r_{12} 0.76 * *$ & $r_{12} 0.92 * *$ \\
correlation & $r_{13}-0.07$ & $r_{13} 0.21$ & $r_{13}-0.79 * *$ & $r_{13}-0.92 * *$ \\
study & $r_{14} 0.06$ & $r_{14}-0.55 * *$ & $r_{14} 0.73 * *$ & $r_{14}-0.89 * *$ \\
& $r_{15} 0.01$ & $r_{15} 0.08$ & $r_{15} 0.90 * *$ & $r_{15}-0.94 * *$ \\
& $r_{23}-0.05$ & $r_{23} 0.08$ & $r_{23}-0.79 * *$ & $r_{23}-0.88 * *$ \\
& $r_{24} 0.05$ & $r_{24} 0.09$ & $r_{24}-0.59 * *$ & $r_{24}-0.96 * *$ \\
& $r_{25} 0.07$ & $r_{25} 0.01$ & $r_{25} 0.73 * *$ & $r_{25}-0.93 * *$ \\
& $r_{34} 0.01$ & $r_{34} 0.10$ & $r_{34} 0.58 * *$ & $r_{34} 0.87 *$ \\
$r_{35} 0.07$ & $r_{35} 0.39 * * 66^{*}$ & $r_{45} 0.75 * *$ & $r_{45}$ & $0.93 * *$ \\
\hline
\end{tabular}

Notes: $r_{12}$, Correlation between $X_{1}$ and $X_{2}: r_{13}$ Correlation between $X_{1}$ and $X_{3}: r_{14}$ Correlation between $X_{1}$ and $X_{4}: r_{15}$ Correlation between $X_{1}$ and $X_{5}: r_{23}$ Correlation between $X_{2}$ and $X_{3}: r_{24}$ Correlation between $X_{2}$ and $X_{4}: r_{25}$ Correlation between $X_{2}$ and $X_{5}: r_{34}$ Correlation between $X_{3}$ and $X_{4}: r_{35}$ Correlation between $X_{3}$ and $X_{5}: r_{45}$ Correlation between $\mathrm{X}_{4}$ and $\mathrm{X}_{5}$. *** Correlation is significant at the 0.01 level (two-tailed). *Correlation is significant at the 0.05 level (two-tailed). 
Table 5 Biomarkers of oxidative stress and nitrites in the lens of cataract patients

\begin{tabular}{lll}
\hline Item & $\begin{array}{l}\text { Idiopathic } \\
\text { cataract }\end{array}$ & $\begin{array}{l}\text { Nitroglycerin } \\
\text { users with cataract }\end{array}$ \\
\hline SOD $(\mathrm{U} / \mathrm{mL})$ & $5.5 \pm 0.2$ & $4.7 \pm 0.2^{*}$ \\
$\mathrm{GSH}(\mu \mathrm{mol} / \mathrm{mL})$ & $1.9 \pm 0.1$ & $1.3 \pm 0.1^{*}$ \\
$\mathrm{CD}(\mathrm{nmol} / \mathrm{mL})$ & $15.8 \pm 0.9$ & $18.1 \pm 1.4^{*}$ \\
TBARS $(\mathrm{nmol} / \mathrm{mL})$ & $2.2 \pm 0.1$ & $3.3 \pm 0.1^{*}$ \\
Nitrite $(\mu \mathrm{mol} / \mathrm{L})$ & $3.4 \pm 0.3$ & $5.7 \pm 0.3^{*}$ \\
\hline
\end{tabular}

Notes: Values are presented as mean $\pm S D, P<0.05, n=60$ for each group. *Significance compared with idiopathic cataract.

Abbreviations: $\mathrm{CD}$, conjugated dienes; GSH, reduced glutathione; SD, standard deviation; SOD, superoxide dismutase; TBARS, thiobarbituric acid reacting substances.

( $14 \%$ and $54 \%$, respectively). However, the cardiac patients treated with nitroglycerin showed a significant decrease in the concentration of lens SOD, compared with the idiopathic cataract patients $(15 \%)$. In addition, the concentration of lens GSH, a marker of nonenzymatic antioxidant activity, was found to be significantly decreased in the cardiac patients treated with nitroglycerin compared with the idiopathic cataract patients (29\%), and the concentration of lens nitrite was found to be significantly higher in the cardiac patients treated with nitroglycerin compared with the idiopathic cataract patients (68\%) (Table 5).

Table 6 illustrates that several biochemical parameters (GSH, SOD, TBARS, CD, and nitrite) in the blood and lens in both the idiopathic cataract patients and the cardiac patients treated with nitroglycerin demonstrated a significant positive correlation.

\section{Discussion}

The current study was designed to evaluate the role of $\mathrm{NO}$ (as a metabolite of nitroglycerin) in the pathogenesis of cataract and to determine the levels of an NO metabolite (nitrite), lipid peroxidation, $\mathrm{SOD}$, and reduced glutathione (GSH) as an indicator of oxidative stress.

NO and NO-derived RNS can damage and kill cells through many mechanisms such as inactivation of respiratory

Table 6 Correlation between the levels of different biochemical parameters in the blood and lens in cataract patients

\begin{tabular}{lll}
\hline Item & $\begin{array}{l}\text { Idiopathic } \\
\text { cataract }\end{array}$ & $\begin{array}{l}\text { Nitroglycerin } \\
\text { users with cataract }\end{array}$ \\
\hline CD & $0.88^{* *}$ & $0.58^{* *}$ \\
Nitrite & $0.59 * *$ & $0.76 * *$ \\
SOD & $0.96 * *$ & $0.91 * *$ \\
GSH & $0.43^{* *}$ & $0.85 * *$ \\
TBARS & $0.72 * *$ & $0.70 * *$ \\
\hline
\end{tabular}

Note: ${ }^{* *}$ Correlation is significant at the 0.01 level (two-tailed).

Abbreviations: $\mathrm{CD}$, conjugated dienes; GSH, reduced glutathione; $\mathrm{SOD}$, superoxide dismutase; TBARS, thiobarbituric acid reacting substances. chain complexes, inhibition of DNA and protein synthesis, decreasing the activity of antioxidative enzymes, intracellular GSH, and adenosine triphosphate, and inactivation of genes by inducing DNA methylation, and irreversible oxidative modification and degradation of DNA, proteins, and membrane lipids. ${ }^{18}$ There are several reports concerning the effects of NO in the eye. NO has been implicated in the development of certain ocular diseases, such as glaucoma and retinal diseases. However, the action of NO in the lens has not yet been completely established. Yamamoto et $\mathrm{al}^{38}$ have studied the localization of nitric oxide synthase in the lens epithelium. However, few published studies have investigated the relationship between NO and cataract. Paik and Dillon ${ }^{21}$ have demonstrated that nuclear cataract may be induced by nitrite, a by-product of NO that causes protein alterations in the lens.

In the current study, serum nitrite levels were found to be significantly increased in the idiopathic cataract patients compared with the control group (18\%). Cardiac patients who received nitroglycerin showed a significant increase in serum nitrite (1.6-fold), compared with the idiopathic cataract patients (44\%) and the control group (70\%). This finding is in agreement with Ornek et al, ${ }^{39}$ who found that NO has a role in the development of cataract.

Inomata et $\mathrm{a}^{40}$ found that aminoguanidine, a nitric oxide synthase inhibitor, inhibits the formation of cataract in a hereditary cataract model. Previous animal studies have demonstrated that there is an association between nuclear cataract and the NO molecule, but observed lower NO levels in such cataracts compared with those in other tissues. ${ }^{21,40}$ iNOS is rapidly activated in pathological processes by inflammation and cytokines. Subsequently, synthesis of significant amounts of $\mathrm{NO}$ occurs for long periods. $\mathrm{NO}$ is then metabolized into nitrite, peroxynitrite, and other free radicals, which initiate pathologic processes including cataract. It is thought that the possible causative factors of posterior subcapsular cataracts may, in many cases, involve activation of the iNOS enzyme in the ocular tissues, particularly in the anterior segment. ${ }^{41}$

Higher levels of NO have been found in the aqueous humor and blood of diabetic patients. ${ }^{41}$ Yilmaz et al ${ }^{42}$ found that patients suffering from proliferative diabetic retinopathy have elevated $\mathrm{NO}$ levels in their vitreous humor. As the aqueous humor is the major source of nutrition for the lens, these increased levels of NO may freely affect the lens and induce development of cataract in such patients. In accordance with these results, previous studies found higher nitrite levels in the cataractous lenses of patients with either diabetes or 
systemic hypertension. These findings suggest a possible role of systemic diseases, especially those involving elevated NO levels, in the pathology of lens opacification in human eyes. ${ }^{39}$ Elevated NO levels in patients with cataractous lenses, especially in patients with posterior subcapsular cataract and hypertension, suggest a possible role for NO in the development of human cataracts. It can be concluded that NO is likely involved in the pathogenesis of human cataracts. ${ }^{41}$

Increased generation of free radicals and decreased antioxidant activity have been proposed to play a major role in the development of age-related cataract. ${ }^{43}$ In addition, Micelli-Ferrari et $\mathrm{al}^{44}$ found that the degree of lens opacity is related to the local level of preoxidative products. Serum TBARS and CD are a measure of systemic oxidative damage. In the present study, the significantly elevated level of serum TBARS in the idiopathic cataract patients provides evidence for the systemic imbalance of lipid redox status. On the other hand, plasma SOD activity was significantly decreased in these patients, which correlated well with the fact that a reduction in antioxidant defenses might be responsible for deviating the systemic redox balance toward oxidative stress that is a possible cause of cataract formation. In agreement with these results, Chakraborty et al ${ }^{43}$ demonstrated a significant reduction in SOD activity in cataract patients. In the current study, serum CD and TBARS, which are markers for oxidative stress, were found to be significantly increased in the idiopathic cataract patients compared with the control group (53\% and 15\%, respectively). Cardiac patients who had received nitroglycerin showed a significant increase in serum CD and TBARS, compared with the idiopathic cataract patients (11\% and $73 \%$, respectively) and the control group (70\% and $98 \%$, respectively).

It can be proposed that a successful alteration in an adaptive phenomenon against oxidative stress caused an elevation in the levels of plasma SOD in the aged persons. However, the cataract patients could not have had such an adaptive response to oxidative stress and demonstrated a significant decrease in SOD activity. This could have resulted from either genetic or environmental factors, or both. ${ }^{43}$ In the present study, the levels of plasma SOD, a marker of enzymatic antioxidant activity, were found to be significantly decreased in the idiopathic cataract patients compared with the control group (22\%).

GSH is a potent antioxidant present in a clear lens and is severely reduced in cataract. ${ }^{45}$ In the present study, the levels of serum GSH, a marker of nonenzymatic antioxidant activity, were found to be significantly decreased in the idiopathic cataract patients compared with the control group (12\%).
Cardiac patients who received nitroglycerin showed a significant decrease in serum GSH, compared with the idiopathic cataract patients (32\%) and the control group (40\%).

\section{Conclusion}

We conclude that plasma SOD, serum reduced GSH, nitrite, and lipid peroxidation activity could be good predictors for the development of cataracts due to systemic redox imbalance caused by chronic administration of nitroglycerin in cardiac patients. NO, as a metabolite of nitroglycerin, played an important role in the pathogenesis of cataracts in cardiac patients who were administered nitroglycerin. Further studies are needed to establish the role of nitroglycerin in the genesis of cataracts.

\section{Limitations of the study}

There are limitations to this study. It is essential to increase the sample size in future studies by collaborating with multiple hospitals all over Saudi Arabia. There are likely more cataract patients, especially elderly patients, who do not attend hospital and they might not be represented by the population studied here.

Despite its small size, this study suggests that those who are administered nitroglycerin should receive antioxidants during their treatment and undergo periodic ophthalmological examinations.

\section{Acknowledgment}

The authors would like to express their deep thanks to Khawlah H Al-Sulaim, a student in the College of Pharmacy, Qassim University, Kingdom of Saudi Arabia, who helped with the collection of data.

\section{Disclosure}

The authors report no conflicts of interest in this work.

\section{References}

1. Zaher C, Goldberg GA, Kadlubek P. "Estimating angina prevalence in a managed care population". Am J Manag Care. 2004;10(11 Suppl): 339-346.

2. Daiber A, Wenzel P, Oelze M, Schuhmacher S, Jansen T, Münzel T. Mitochondrial aldehyde dehydrogenase (ALDH-2) - maker of and marker for nitrate tolerance in response to nitroglycerin treatment. Chem Biol Interact. 2009;178(1-3):40-47.

3. Zhang X, Chang L, Zhang Y, Deng S, Li Y, Peng J. Comparing the role of glutathione-S-transferase and mitochondrial aldehyde dehydrogenase in nitroglycerin biotransformation and the correlation with calcitonin gene-related peptide. Eur J Pharmacol. 2009;617(1-3):97-101.

4. Mao M, Sudhahar V, Ansenberger-Fricano K, et al. Nitroglycerin drives endothelial nitric oxide synthase activation via the phosphatidylinositol 3-kinase/protein kinase B pathway. Free Radic Biol Med. 2012;52(2):427-435. 
5. Kollau A, Beretta M, Russwurm M, et al. Mitochondrial nitrite reduction coupled to soluble guanylate cyclase activation: lack of evidence for a role in the bioactivation of nitroglycerin. Nitric Oxide. 2009;20(1): 53-60.

6. Chen Z, Zhang J, Stamler JS. Identification of the enzymatic mechanism of nitroglycerin bioactivation. Proc Natl Acad Sci US A. 2002; 99(12):8306-8311.

7. McDonald BJ, Bennett BM. Biotransformation of glyceryl trinitrate by rat aortic cytochrome P450. Biochem Pharmacol. 1993;45(1):268-270.

8. O’Byrne S, Shirodaria C, Millar T, Stevens C, Blake D, Benjamin N. Inhibition of platelet aggregation with glyceryl trinitrate and xanthine oxidoreductase. J Pharmacol Exp Ther. 2000;292(1):326-330.

9. Lau DT, Chan EK, Benet LZ. Glutathione S-transferase-mediated metabolism of glyceryl trinitrate in subcellular fractions of bovine coronary arteries. Pharm Res. 1992;9(11):1460-1464.

10. Feelisch M, Kelm M. Biotransformation of organic nitrates to nitric oxide by vascular smooth muscle and endothelial cells. Biochem Biophys Res Commun. 1991;180(1):286-293.

11. Lincoln TM, Dey N, Sellak H. Invited review: cGMP-dependent protein kinase signaling mechanisms in smooth muscle: from the regulation of tone to gene expression. J Appl Physiol. 2001;91(3):1421-1430.

12. Daiber A, Oelze M, Sulyok S, et al. Heterozygous deficiency of manganese superoxide dismutase in mice (Mn-SOD+/-): a novel approach to assess the role of oxidative stress for the development of nitrate tolerance. Mol Pharmacol. 2005;68(3):579-588.

13. Daiber A, Oelze M, Coldewey M, et al. Oxidative stress and mitochondrial aldehyde dehydrogenase activity: a comparison of pentaerythritoltetranitrate with other organic nitrates. Mol Pharmacol. 2004;66(6): 1372-1382.

14. Sydow K, Daiber A, Oelze M, et al. Central role of mitochondrial aldehyde dehydrogenase and reactive oxygen species in nitroglycerin tolerance and crosstolerance. J ClinInvestig. 2004;113(3):482-489.

15. Steinmetz CG, Xie P, Weiner H, Hurley TD. Structure of mitochondrial aldehyde dehydrogenase: the genetic component of ethanol aversion. Structure. 1997;5(5):701-711.

16. Gori T, Parker JD. Nitrate tolerance: a unifying hypothesis. Circulation. 2002;106(19):2510-2513.

17. Munzel T, Sayegh H, Freeman BA, Tarpey MM, Harrison DG. Evidence for enhanced vascular superoxide anion production in nitrate tolerance: a novel mechanism underlying tolerance and cross-tolerance. J Clin Invest. 1995;95(1):187-194.

18. Klatt P, Lamas S. Regulation of protein function by S-glutathiolation in response to oxidative and nitrosative stress. Eur J Biochem. 2000; 267(16):4928-4944.

19. Rassaf T, Bryan NS, Kelm M, Feelisch M. Concomitant presence of $\mathrm{N}$-nitroso and S-nitroso proteins in human plasma. Free Radic Biol Med. 2002;33(11):1590-1596.

20. Feelisch M, Rassaf T, Mnaimneh S, et al. Concomitant S-, N-, and heme-nitros(yl)ation in biological tissues and fluids: implications for the fate of NO in vivo. FASEB J. 2002;16:1775-1785.

21. Paik D, Dillon J. The Nitrite/alpha crystallin reaction: a possible mechanism in lens matrix damage. Exp Eye Res. 2000;70(1):73-80.

22. Trinder P. Determination of glucose in blood using glucose oxidase with an alternative oxygen acceptor. Ann Clin Biochem. 1969;6(1):24-27.

23. Little RR, Wiedmeyer HM, England JD, et al. Interlaboratory standardization of measurements of glycohemoglobins. ClinChem. 1992;38(12): 2472-2478.

24. Schuster HG, Pilz K. Colorimetric micromethod for the determination of non esterified long-chain fatty acids in serum. Z Med Lab Diagn. 1979; 20(4):212-217.
25. Deeg R, Ziegenohrm J. Kinetic enzymatic method for automated determination of total cholesterol in serum. J Clin Chem. 1983; 29(10):1798-1802.

26. Fossati P, Prencipe L. Serum triglycerides determinedColourimetrically with an enzyme that produces hydrogen peroxide. Clin Chem. 1982; 28(1):2077-2080.

27. Norbert WT. Clinical Guide to Laboratory Tests. 3rd ed. Philadelphia, PA: Saunders W.B. Company; 1995.

28. Friedewald WT. Estimation of concentration of low-density lipoprotein cholesterol in plasma without use of the preparative ultracentrifuge. Clin Chem. 1972;18(7):499-502.

29. Griess L, Wagner D, Glogowski J, Skipper P, Wishnok J, Tannenbaum S. Analysis of nitrate, nitrite, and [15N] nitrate in biological fluids. Anal Biochem. 1982;126(1):131-138.

30. Recknagel RO, Glende EA. Spectrophotometric detection of lipid conjugated dienes. Methods Enzymol. 1984;105:331-337.

31. Satoh K. Serum lipid peroxide in cerebrovascular disorders determined by a new colorimetric method. Clin Chim Acta. 1978;90(1):37-43.

32. Kakkar PB, Das B, Viswanathan PN. A modified spectrophotometric assay of superoxide dismutase. Indian J Biochem Biophys. 1984;21(2): $130-132$.

33. Hissin PJ, Hilf RA. A fluorometric method for determination of oxidized and reduced glutathione in tissues. Anal Biochem. 1976;74(1):214-226.

34. Chajès V, Sattler W, Stultschnig M, Kostner G. Photometric evaluation of lipid peroxidation products in human plasma and copper oxidized low density lipoproteins: correlation of different oxidation parameters. Atherosclerosis. 1996;121(2):193-203.

35. Buege JA, Aust SD. Microsomal lipid peroxidation. Methods Enzymol. 1978;52:302-310.

36. Misra HA, FridovichI. The role of superoxide anion in the autoxidation of epinephrine and a simple assay for superoxide dismutase. $J$ Biol Chem. 1972;247(10):3170-3175.

37. Beutler E, Duron O, Kelly BM. Improved method for the determination of blood glutathione. J Lab Clin Med. 1963;61:882-888.

38. Yamamoto R, Bredt D, Snyder S, Stone R. The localization of nitric oxide synthase in the rat eye and related cranial ganglia. Neuroscience. 1993;54(1):189-200.

39. Ornek K, Karel F, Büyükbingöl Z. May nitric oxide molecule have a role in the pathogenesis of human cataract? Exp Eye Res. 2003; 76(1):23-27.

40. Inomata M, Hayashi M, Shumiya S, Kawashima S, Ito Y. Aminoguanidinetreatment results in the inhibition of lens opacification and calpainmediated proteolysis in Shumiya Cataract Rats (SCR). J Biochem. 2000;128(5):771-776

41. Aydın A, Orhan H, Sayal A, Ozata M, Sahin G, Işimer A. Oxidative stress and nitric oxide related parameters in type 11 diabetes mellitus: effects of glycemic control. Clin Biochem. 2001;34(1):65-70.

42. Yilmaz G, Esser P, Kociek N, Aydin P, Heimann K. Elevated vitreous nitric oxide levels in patients with proliferative diabetic retinopathy. Am J Ophthalmol. 2000;130(1):87-90.

43. Chakraborty I, Kunti S, Bandyopadhyay M, Dasgupta A, Chattopadhyay G, Chakraborty S. Evaluation of serum zinc level and plasma SOD activity in senile cataract patients under oxidative stress. Indian J Clin Biochem. 2007;22(2):109-113.

44. Micelli-Ferrari T, Vendemiale G, Grattagliano I, et al. Role of lipid peroxidation in the pathogenesis of myopic and senile cataract. $\mathrm{Br} J$ Ophthalmol. 1996;80(9):840-843.

45. Miric D, Kisic B, Zoric L, Mitic R, Miric B, Dragojevic I. Xanthine oxidase and lens oxidative stress markers in diabetic and senile cataract patients. J Diabetes Complications. 2013;27(2):171-176. 


\section{Publish your work in this journal}

Therapeutics and Clinical Risk Management is an international, peerreviewed journal of clinical therapeutics and risk management, focusing on concise rapid reporting of clinical studies in all therapeutic areas, outcomes, safety, and programs for the effective, safe, and sustained use of medicines. This journal is indexed on PubMed Central, CAS,

EMBase, Scopus and the Elsevier Bibliographic databases. The manuscript management system is completely online and includes a very quick and fair peer-review system, which is all easy to use. Visit http://www.dovepress.com/testimonials.php to read real quotes from published authors.

Submit your manuscript here: http://www.dovepress.com/therapeutics-and-clinical-risk-management-journal 